
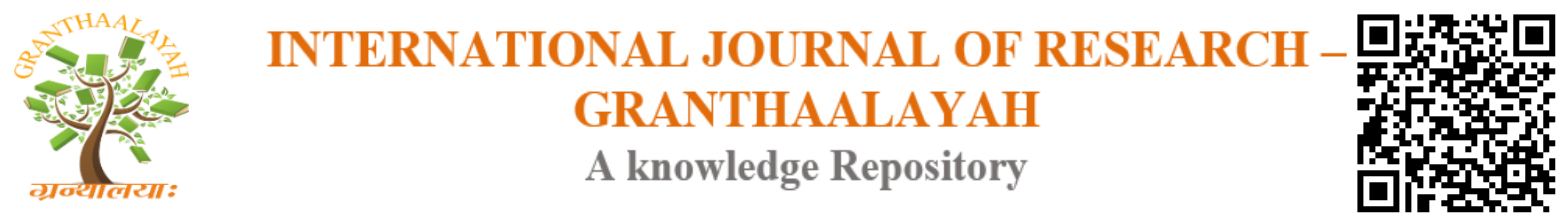

Science

\title{
SAFETY IMPROVEMENT THOUGHTS IN MINING INDUSTRIES
}

\author{
G. Nageswara Rao *1 \\ ${ }^{* 1}$ AMIE (Mining. E), \& P.G Dip. in Env Studies, India
}

\begin{abstract}
Mining industry associated with many type of technical involvement i.e. from low to high and run by unskilled, semi-skilled, skilled and technically skilled manpower oriented. The efficiency of this industry is mainly depending on safety of work force. Productivity is proportionate to safety of workmen, machinery and working site etc. The safety is better in the mine then it gets best productivity. The accident analysis in mining industry reveals that prime cause is lack of personal safety. When the safety thoughts roaming in the minds of work force as well as in management will always make the industry way leading to safe so that personal safety also good. The personal safety of workmen is influenced by internal and external agencies of behavioral attitude stress that is at home and at work site.

In this paper explained some of safety tips particularly on personal safety matters inside and outside of the work site and behavioral attitude required for work force towards achieving goal of industry motive towards reach of Zero Hazardous, Zero Incidents and Zero losses.
\end{abstract}

Keywords: Safety; Mining; Industries.

Cite This Article: G. Nageswara Rao. (2018). "SAFETY IMPROVEMENT THOUGHTS IN MINING INDUSTRIES." International Journal of Research - Granthaalayah, 6(12), 159-167. https://doi.org/10.29121/granthaalayah.v6.i12.2018.1104.

\section{Introduction}

Mining is the extraction of valuable minerals or other geological materials from the earth, usually from an ore body, lode, vein, seam, reef or placer deposit. These deposits form a mineralized package that is of economic interest to the miner. There are four main mining methods: underground, open surface (pit), placer, and in-situ mining. Underground mines are more expensive and are often used to reach deeper deposits. Surface mines are typically used for shallower and less valuable deposits. The method of mining is developed for exploitation of minerals not only in earth crust also in astrological bodies outside the earth and under the sea etc. The mining industry has a reputation for being a risky business, with health risks that are varied and often quite serious and it is important for miners to protect themselves accordingly. Nevertheless, mining doesn't have to be unsafe. With the introduction of strict safety legislation and protocol, as well as advances in safety equipment, the industry has seen its fatality rate drop 
over time. Although the goal of zero harm has not yet been achieved, it remains the standard that mining companies continue to strive towards.

\section{Health and Safety in the Mining Industry}

Occupational health and safety hazards whether they are physical, chemical, biological, mechanical or psychological, can affect any industry be it agriculture, construction, manufacturing units and even the healthcare sector. However, the one industry most commonly and severely affected is the mining industry. With increasing demand of minerals, more and more people are employed in this industry which involves hazardous tasks and thus, proper safety training and measures are required to protect the workers from the dangerous diseases or disabilities that can result from them. The various factors that pose a threat to mine workers include injuries by accidents, exposure to dust, chemicals, toxic fumes, extreme temperature or humidity, noise and vibration and so forth. Apart from these, the possibility of fire, explosion, flood or collapse can lead to large scale destruction and thus, mining safety occupies a vital place in the functioning of the industry.

The training of mine workers aims at the following:

- Providing clear instructions on the procedures and on handling equipment.

- Training is necessary on safety precautions required while working.

- Identifying the risk factors and ways to avoid them.

- Mandatory use of machine guards, masks, gloves and other protective gear while working or handling equipment.

- Training on combating emergencies, if any. Special lifting training as lifting heavy or oversized loads can lead to spinal injuries and pose a risk to the health of the employees.

- Provision and usage of personal protective equipment (PPE) such as helmets, safety glasses, respirators, face shields, ear plugs etc. while at work.

- Proper care, maintenance and disposal of PPE's.

With different countries making efforts and laws to safeguard the health and safety of mine workers, In India established Mines Act, 1952

The preamble of the Act laid down that it "an Act to amend and consolidate the law relating to the regulation of labour and safety in mines".

The Act consists of 88 sections in 10 chapters. The Mines Act, 1952 is a sort of welfare legislation which prescribes the laws relating to the regulation of labour and their safety in mines. The act also regu $\neg$ lates for carrying out mining operations and management of mines. It lays down the basic provisions for health and safety of people em $\neg$ ployed in mines and regulates their working conditions. It also has provisions relating to in $\neg$ spection of mines and procedure of reporting to be followed.

Sec. 8 - powers of special officers to enter, measure etc.

Sec. 9 - facilities to be afforded to Inspectors

Sec.19 - Provisions for drinking water

Sec. 28 - Weekly day of Rest

Sec. 29 - Compensatory day of Rest

Sec. 30 - Hours of work above the ground 
Sec.31 - Hours of work below the ground

Sec. 40 - employment of persons below 18 years of age

Sec. 45 - prohibition of presence of persons below 18 years of age in a mine

The main objectives of this act was to protect the health and safety of mine employees by ensuring owner's responsibility to provide health and safety training, identifying hazardous factors, investigating and eliminating them, controlling and minimizing the risk to employees, employing hygienists, providing medical attention etc. With regulations of the Mines Act 1952 and it related Mines rules, Mines regulations and amendment their of time to time, shows that improvement of health and safety was witnessed in the performance of Indian Mining Industry. As the mining environment poses much higher risks to its workers as compared to other industries, it requires thorough understanding and awareness in order to prevent the occurrences of accidents or illnesses at the workplace. The national conferences on safety taking big role on avoiding of major accidents in mining by promoting guidelines for corrective steps to improve safety and health practices of employees in mining industry.

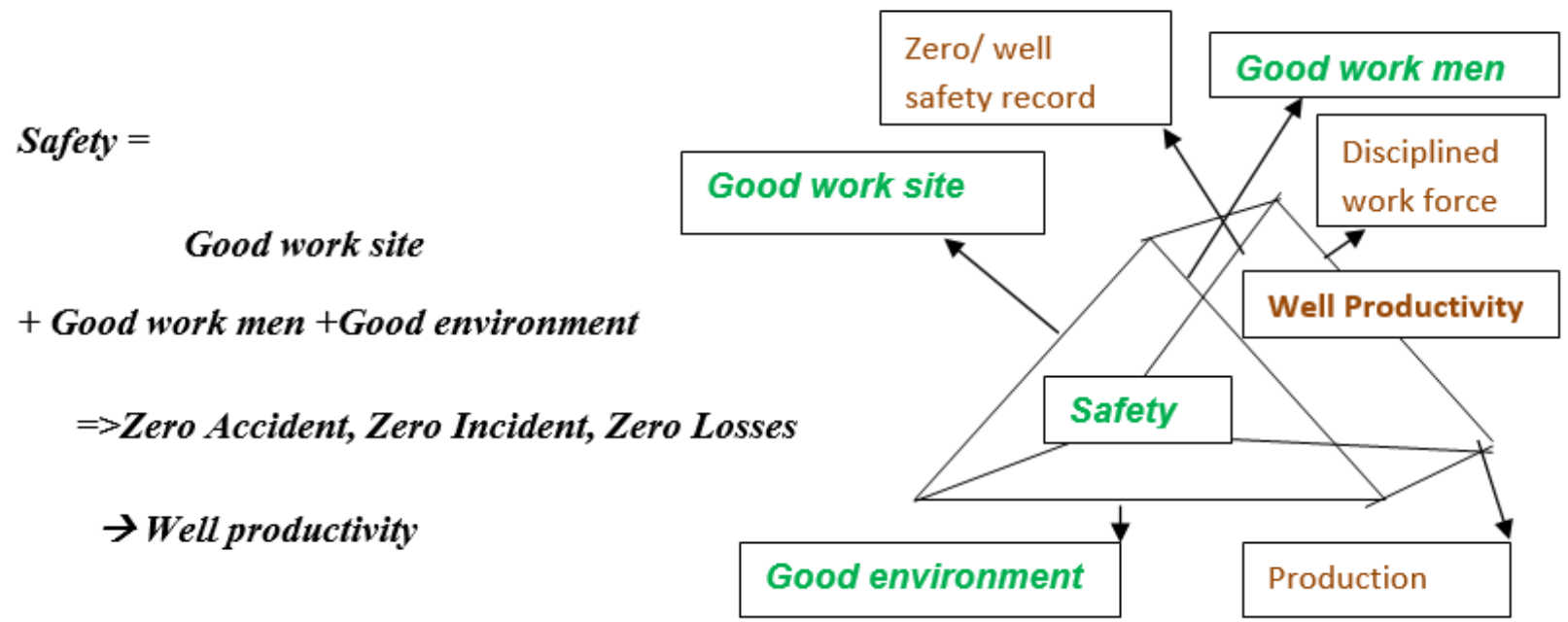

The foundation of any successful workplace safety effort is one that encourages employees to identify unsafe behaviors and opportunities for improvement while also making wellinformed safety decisions during daily routine tasks. This step requires knowing the particular hazards of your job or workplace.

What is Safety? Safety is the elimination of the risk existing in work place, is at home or at industry or any other place to a person present in that time by providing best room of environment.

\section{What are the causes of risk?}

Every activity of mankind is the risk bind, it may cause harm/not harm sometimes/occasional to the person involved in this activity. But everybody should be hope that the activity may complete with desired target without any harm.

The every activity task has associated with safety laws, regulations and standard procedures to avoid risk. 
The risk in job may cause direct and indirect losses to the workmen and mine management:

Direct risk :- Risk associated with nature of job to be performed, with related work place condition, machinery condition and time of exposure etc.

Indirect risk :- Risk associated with behavioral condition of a person for example a person sleep less driving or restless driving may leads to very risk.

Some general safety rules:

- Keep left side of the road always no risk

- Using foot path for pedestrians always safe

- Zebra line crossing always safe

- Drunken \& drive very risky

- avoid over speed, it may cause to accident

Above simple safety thought keeping in mind will always protect the travelling person on the road.

Following general precautionary measure protect persons from job risk:

\section{General Precautions}

Your safety is your personal responsibility.

Always follow the correct procedures.

Never take shortcuts.

Take responsibility and clean up if you made a mess.

Clean and organize your workspace.

Ensure a clear and easy route to emergency exits and equipment.

Be alert and awake on the job.

Everybody has to know that Safety starts from home; it should not be ever end

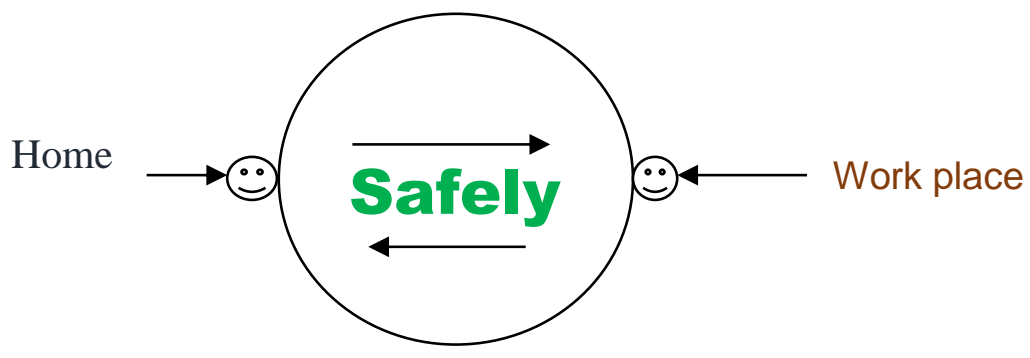

Failure in safety at home indirectly effect the industry

- In the form of man shifts lost in absences of skill work men leads to reduction on production.

- Home sick/stress leads to increase risk at work, sometimes it may harm to himself of workmen or otherwise to co- worker or machinery or might be made unsafe of the working site to next shift workers.

Safety at home purely may not be depends on workmen and his family. But the management part also ply very curial role to make safe worker at his home, the personal/HR to ply key role to give publicity/propaganda, education and guidance on personal issues. 
How to safe in Home?

DOI: 10.5281/zenodo.2539576

- Maintenance of good housing \& house keeping

- Maintenance good relationship with his family \& neighbor

- Follow good health practices like yoga, walking and aerobic exercises \& Good food habits

- Take regular medication if required, prefer for ayurvedic

- Planning good education \& well settlements to family dependents

- Taking proper rest for peaceful mind

- Don't take over load on head like external business etc.

- Consume plenty of warm water daily

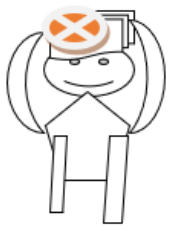

- Try to spend more time in greenery place or try to build greenery on your surrounding of home

- Always to keep oxygen giving plants outdoor \& indoor area of home

- Avoid waste burning, follow the best waste maintenance methods

- Avoid use of plastic as package/ covers for carry the food materials

- Maintenance of good sanitation facilities

\section{Safety in Outside the Home}

- Wear safety gadgets during driving,

- Using bicycle for short distances is best for health as well as surrounding atmosphere

- Punctual time maintenance is the best practice for reduce the fatigue stress.

- Don't try to work complete in hurry burry.

- Avoiding consuming of alcohol \& smoking is better than control

- Better planning on financial matters

- Avoid external business as possible

\section{Safety at Work Place}

Commonly the safety fails at work place due to:

- Failure to identify omission/mistakes at worksite

- -Failure to assess the risk attitude and it's mitigate or control methods

- -Failure to timely decision by worker him-self/co worker/ supervisor

- -Negligence, over-sighting situations and wrong interpretation

\section{How to keep Work Place in Safe Condition}

- Always follow SOP

- Observation of work site carefully in view safety

- Beware of elevated loads if any or if possible, avoid it

- Follow traffic rules in haul roads as well in underground running $\mathrm{M} / \mathrm{C}$

- Use the machinery which is in fit for that work

- Don't post-phone/avoid M/C maintenance

- Make work vicinity in fall proof/fail proof

- Always keep way to safe zone

- Follow 5s concept

- Knowing the work procedure well

- be prepare about work 
- taking accountability and responsibility for safe working

- safety talk/education before starting of work at site

\section{Role of Mine Management on Creating Safe Environment out of the Work Site}

- Provision of well residential facilities to employee $\&$ his family

- Provision of well education \& hospital facilities to employee $\&$ his family

- Provision of well recreation facilities to relive work stress after duty hours

- Provision of education, training \& Skill developed centers for employee family members

- Provision well sanitary facilities like mosquitos' control, chlorination and municipal solid waste centers

- Provision of common waste water treatment plants and treated common drinking water supply system.

- Provision of entertainment facilities like playground, swimming pool and market malls etc.

- Provision of awareness centers to motivate good health practices and avoiding alcoholic consumption and smoking

Even though some of the variable's negative affectivity, job dissatisfaction, and risk-taking behaviors are therefore crucial in avoiding accident/injuries in mines.

"Understanding and being aware of your environment is the first step to preventing illness or injury in the workplace," reveals mining medicine researcher Megan Clark, who outlines the following 7 common health risks to watch out for in the mining industry.

\section{1) Coal Dust}

Dust inhalation or coal dust is one of the most common concerns for miners. "The ongoing inhalation of coal dust can cause what is colloquially known as 'miner's lung' or 'black lung'. Miner's lung is a form of the occupational lung disease group pneumoconiosis. It varies in severity, but symptoms include shortness of breath and scarring of lung tissue, which can cause ongoing respiratory issues," says Clark.

Even though measures to prevent black lung have been legally enforced for many years now, new cases still occur among coal miners. Mining companies need to develop a dust control plan, and supervisors should ensure that dust control systems are working properly for every production shift. Mine workers should be trained on the hazards of over-exposure to coal mine dust. Respiratory protection should be used when dust control protection is being installed, maintained or repaired. Medical screening and surveillance are also essential.

\section{2) Noise}

Mines are noisy places, with the constant of drilling and heavy machinery, and the potential for hearing damage is quite serious. "It can be easy for you to mentally get used to loud noises, but that doesn't mean that damage isn't still being done. Many people don't notice the damage to their hearing until long after they were first exposed to the noisy environment, as most damage occurs very slowly. Over-exposure to excessive noise can result in tinnitus (ringing in the ears), sleep disturbances, concentration problems and even permanent hearing loss," Clark explains. 
To protect workers against noise, mining companies should evaluate working conditions and noise exposure through risk assessments. Avoiding and reducing exposure can be achieved by applying engineering controls at the noise source or along the noise path to reduce exposures, such as vibration dampeners or absorptive panels. Regular maintenance of machines is also essential to reducing noise. Employer must ensure proper use of personal hearing protection amongst noiseexposed employees, while providing necessary health and safety training and maintaining up-todate health surveillance records.

\section{3) Whole Body Vibration}

Whole body vibration (WBV) is a slow forming physical hazard that occurs in mining workers and other occupations that work with heavy machinery. "In the mining environment, WBV can be caused either by spending a lot of time sitting on machinery, which is most of the time in mining extraction, or by standing, such as working on jumbo operators. Some forms of vibration are ok, but they become dangerous when they involve uneven surfaces, vehicle activity such as ripping versus pushing material in a bulldozer, and engine vibrations. Symptoms of WBV include musculoskeletal disorders, reproductive damage in females, vision impairment, digestive problems and cardiovascular changes," Clark outlines.

Again, reducing exposure also reduces the health risks and should be the first step that mining companies take. This might include filling in potholes on unmade roads, minimising the transport of goods or materials, or replacing manned with unmanned machines such as remotely controlled conveyors. Where risks cannot be avoided, supervisors should reduce the time for which the employee uses the machine each day. Instruction and training are critical, and symptoms of back pain in employees should be closely monitored.

\section{4) UV Exposure}

For open-pit miners, understanding the risk of over-exposure to UV (ultraviolet) radiation in sunlight is essential. "Over exposure of ultraviolet rays can put you at risk of skin cancer, of which Australia has the highest rate in the world. Not only can UV rays cause melanomas to form, but they can cause serious damage to your eyes if you are not wearing protective eye wear. In the short-term, overexposure to the sun can cause dehydration, headaches and nausea. Mine workers often spend whole days out in the baking hot sun, so are naturally at a very high risk of developing cancer and eye problems if they are not adequately protected," Clark explains.

Employers should conduct a risk assessment on outdoor work scheduled to assist in developing appropriate sun protection measures. The most effective way of reducing UV exposure is to use a combination of protection methods, including re-organising work to avoid the UV peak of the day, providing natural or artificial shade, providing appropriate protective clothing, and applying sunscreen. It is also important that employers train employees to raise awareness of the risks associated with exposure to UV and the sun protection measures required. Employers can provide skin cancer checks as part of regular workplace medical examinations and in pre-employment medical checks. 


\section{5) Musculoskeletal Disorders}

Musculoskeletal disorders (MSDs) refer to any problems affecting your bones, muscles, blood vessels and nerves. "Mine workers are exposed to a variety of potential health risks that fall under this broad category. While musculoskeletal damage can occur due to a trip, fall or heavy lift, the more serious ones occur slowly over time. This could be due to ongoing heavy lifting or repetitive strains," says Clark.

Preventing MSDs needs to be a key part of every workplace health and safety program. In safe and healthy workplaces, employers should identify and assess job-related MSD hazards and put in place controls to reduce workers' exposure to MSD hazards. Furthermore, workers should be advised and trained about MSD hazards in their job and workplace and should be encouraged to participate in health and safety programs through early reporting of MSD symptoms or concerns to their supervisors. Employers should follow up to ensure preventative measures are working.

\section{6) Thermal Stress}

A common health risk that miners face is thermal - or heat - stress. "Mining environments are often very hot and humid; particularly in hot country like India, which over time can cause thermal stress in workers. Over exposure to heat and humidity can cause the body to become fatigued and distressed. This can result in heat stroke or more serious ongoing health problems,".

Where there is a possibility of heat stress occurring, companies need to carry out a risk assessment that considers the work rate, working climate and worker clothing and respiratory protective equipment. Where possible, control the temperature using engineering solutions, provide mechanical aids where possible to reduce the work rate, and regulate the length of exposure to hot environments. Furthermore, personal protective equipment should be provided, such as specialised protective clothing that incorporates personal cooling systems or breathable fabrics. Furthermore, companies should provide training for workers, especially new and young employees, and monitor the health of workers at risk.

Employers and supervisors can save the lives of workers in hot environments by following these eight simple steps:

1) Institute a heat acclimatization plan and medical monitoring program. Closely supervise new employees for the first 14 days or until they are fully acclimatized. Most heat-related worker deaths occur in the first 3 days on the job and more than a third occur on the very first day. New and temporary workers are disproportionately affected. If someone has not worked in hot weather for at least a week, their body needs time to adjust.

2) Encourage workers to drink about 1 cup of water every 15-20 minutes. During prolonged sweating lasting several hours, they should drink sports beverages containing balanced electrolytes.

3) Provide shaded or air-conditioned rest areas for cooling down, and empower workers to use them.

4) Provide workers with protective equipment and clothing (such as water-cooled garments, air-cooled garments, hats, ice-packet vests, wetted over-garments, and heatreflective aprons or suits). 
5) Be familiar with heat illness signs and symptoms, and make sure your employees are, too. Some heat exhaustion signs are dizziness, headaches, cramps, sweaty skin, nausea and vomiting, weakness and a fast heartbeat. Heat stroke symptoms include red, hot, dry skin; convulsions; fainting; and confusion. In general, fainting and confusion represent an emergency and should trigger the call for professional evaluation.

6) Encourage workers to recognize heat illness symptoms and notify a supervisor or medical professional if they or other coworkers are showing signs. Implement a buddy system where workers observe each other for early signs and symptoms of heat intolerance.

7) Download OSHA's Heat Safety Tool on your iPhone or Android device to help calculate the heat index, a measurement of how it feels when considering humidity. The app provides specific recommendations for preventing heat illness based on the estimated risk level where you are working.

8) Know what to do in an emergency. Employees should call a supervisor for help. If a supervisor is not available, call 911. Have someone stay with the worker until help arrives.

\section{7) Chemical hazards}

Mine workers are often exposed to harmful chemicals. "As an example, the most common group of chemicals that cause concern in a coal mining environment are polymeric chemicals. Regardless of the chemicals you work in close proximity to, appropriate safety wear and precautions need to be taken to minimise your body's exposure to them. Risks include chemical burns, respiratory problems and poisoning," Each chemical has a unique set of hazards and needs to be handled properly to ensure worker safety, so employers need to conduct risk assessments to establish best practices. A standard operating procedure (SOP) that addresses the use of correct personal protective equipment, safe handling, safe use, and proper disposal should be established. Ventilation is also an important factor in minimizing exposure, as well as general housekeeping and cleanliness. Thorough training and drills should be conducted regarding the company's spill response plans and chemical hygiene plans.

\section{Conclusion}

Every work man will be try to keep him in safe in always, but some of the odd conditions will extracted to break the safe atmosphere, management to be always strive for methods to protect workmen from internal (in job) safety failures and external (at home) safety failures by providing better education with training. The education \& training means not an institutional it should be friendly way, to be interpreted in minds of worker and his family.

\section{THE SAFETY IS VERY PERCIOUS BUT IT IS VERY CHEEP BYING WITH SAFETY RULES SAFETY NEVER LOST BY MANAGING RISK TO ZERO LEVEL}

----G.Nageswara Rao Addl.Mgr/SCCL

\footnotetext{
*Corresponding author.

E-mail address: garidepallinageswarrao@ yahoo.in/nggaridepalli93@ gmail.com
} 